\title{
Gamma Radiation Shielding Properties of Steel and Iron Slags
}

\author{
Ravinder Singh1, Sukhpal Singh², Gurmel Singh1, Kulwant Singh Thind ${ }^{3}$ \\ ${ }^{1}$ Department of Physics, Punjabi University, Patiala, India \\ ${ }^{2}$ Department of Basic and Applied Sciences, Punjabi University, Patiala, India \\ ${ }^{3}$ GuruNanak Dev University, Amritsar, India \\ Email: apravinders@gmail.com
}

How to cite this paper: Singh, R., Singh, S., Singh, G. and Thind, K.S. (2017) Gamma Radiation Shielding Properties of Steel and Iron Slags. New Journal of Glass and Ceramics, 7, 1-11.

http://dx.doi.org/10.4236/njgc.2017.71001

Received: October 11, 2016

Accepted: December 19, 2016

Published: December 22, 2016

Copyright (c) 2017 by authors and Scientific Research Publishing Inc. This work is licensed under the Creative Commons Attribution International License (CC BY 4.0).

http://creativecommons.org/licenses/by/4.0/

\begin{abstract}
Using steel slag and two types of (soft and hard) iron slags, ten samples were prepared. Different gamma radiation interaction parameters were computed theoretically and measured experimentally at different energies: $60 \mathrm{keV}, 136$ $\mathrm{keV}, 662 \mathrm{keV}, 1173 \mathrm{keV}$ and $1332 \mathrm{keV}$ in low and medium energy range using narrow transmission geometry. It has been observed that shielding effectiveness of a sample is inversely proportional to Half Value Layer (HVL). The obtained results were compared with Pure Flyash and it was observed that slag is better aggregate than flyash in shielding radiation as well as in construction applications. The results have been presented in the form of tables and graphs with more useful conclusions.
\end{abstract}

\section{Keywords}

Mass Attenuation Coefficient, Effective Atomic Number, Half Value Layer

\section{Introduction}

Gamma radiation interaction is the most accurate, convenient and a non destructive method of determining the various characteristics of the material. With increasing the use of radioactive isotopes and applications of radiations in many fields such as industry, agriculture, medicine, technology and research, there seems a need to study in depth gamma ray analysis of every material. Gamma ray interaction depends on the extent of absorption or scattering, incident energy, nature of the target material and also on the geometrical conditions. The knowledge of gamma ray interaction parameters [1] of the material provides not only better understanding of the degradation of energy but also a basis for safe handling of what might be admittedly harmful material. The accurate determination of interaction parameters is essential before a given material is used in 
any field. Mass attenuation coefficient [2]-[9] is the basic parameter for understanding the gamma ray interaction with matter. It gives fraction of the energy scattered or absorbed due to interaction with matter. A large number of photon attenuation measurements, calculations and compilations of various elements have been available at National Institute of Standards and Technology, Gaithersburg USA (J.H. Hubbell group) [10]. Different other workers have calculated attenuation coefficients in different categories such as building materials, alloys, marbles, glasses, biological materials and other composite materials.

Effective atomic number $\left(Z_{\text {eff }}\right)$ is another useful important parameter for a composite material. It measures the effect of chemical composition, atomic number as well as abundance of each element in the sample. Therefore, effective atomic number [11]-[16] plays a vital role in the multi-elemental material analysis. According to Hine (1952), "effective atomic number of a material composed of several elements cannot be expressed by a single number and various atomic numbers of elements have to be weighted differently". Following Hine, several authors have conducted $Z_{\text {eff }}$ studies in various composite materials such as alloys, soils, perspex and bakelite, compounds and thermoluminescent dosimetric compounds etc. However, in literature, only a limited amount of work has been reported for $Z_{\text {eff }}$ studies of different types of slags.

Electron density (electron/g) and half value layer (HVL) are two other useful parameters for understanding the interaction of gamma ray. The degradation or attenuation of gamma rays are directly related with electron density [17] [18] as it represents the probability of electron's presence in the material. Half value layer (HVL) determines the thickness required to reduce the intensity to a safe level. It also determines the effectiveness of a material to be used for shielding radiation. Many workers have studied electron densities and HVL for shielding characteristics of materials such as fatty acids, lead oxide, barites and lead-flyash concretes.

On the basis of these computed and measured interaction parameters, an attempt has been made and it is proposed to use iron and steel slags for the shielding of nuclear radiation in preference to flyash.

\section{Theory}

\subsection{Attenuation Coefficients}

A parallel beam of monochromatic radiation is attenuated in matter, its intensity decreases from $I_{0}$ to I according to Lambert-Beer law

$$
I=I_{0} \mathrm{e}^{-\mu x},
$$

where $\rho$ is density and $x$ is thickness of the material. $\mu\left(\mathrm{cm}^{-1}\right)$ is linear attenuation coefficient. Equation (1), can be written as,

$$
I=I_{0} \mathrm{e}^{-(\mu / \rho) \rho x}
$$

where $\mu / \rho\left(\mathrm{cm}^{2} / \mathrm{g}\right)$ is called mass attenuation coefficient, denoted by $\mu_{m}$.

For a composite material,

$$
\mu / \rho=\sum w_{i}(\mu / \rho)_{\mathbf{I}}
$$


where $w_{i}$ and $(\mu / \rho)_{\mathrm{I}}$ are weight fraction and mass attenuation coefficient, respectively, of the constituent element $i$.

\subsection{Effective Atomic Number ( $\left.Z_{\text {eff }}\right)$}

This is another important parameter for the interpretation of attenuation of radiation by composite materials. As atomic number is not constant for different interaction processes in different energy regions, the various atomic numbers of elements present in the sample have to be weighted differently. The effective atomic number, $\left(Z_{\text {eff }}\right)$, can be defined through the following relations;

The total molecular cross-section $\sigma_{t, m}$ can be calculated using the relation

$$
\sigma_{t, m}=\left(\frac{\mu}{\rho}\right) \frac{M}{N_{A}}
$$

where $M=\sum n_{i} A_{i}$ is molar mass. $N_{A}$ is Avogadro number; $n_{i}$ and $A_{i}$ are the number of formula units and atomic weight respectively of $i^{\text {th }}$ element.

The total atomic cross-section $\sigma_{t, a}$ is given by

$$
\sigma_{t, a}=\sigma_{t, m} \frac{1}{\sum n_{i}} .
$$

The total electronic cross-section $\sigma_{t, e l}$ is given by

$$
\sigma_{t, e l}=\frac{1}{N_{A}} \frac{f_{i}}{Z_{i}} A_{i}\left(\frac{\mu}{\rho}\right)
$$

where $f_{i}=\frac{n_{i}}{\sum_{n_{j}}}$ is the fractional abundance of $I^{\text {th }}$ element.

$$
Z_{\text {eff }}=\frac{\sigma_{t, a}}{\sigma_{t, e l}}
$$

where $\sigma_{t, a}$ is the average atomic cross section and $\sigma_{t, e l}$ is the average electronic cross section.

\subsection{Electron Density $\left(N_{e}\right)$}

Electron density is defined as number of electrons per gram in the material. It can be determined from the following relations;

$$
N_{e}=\frac{\mu / \rho}{\sigma_{e}}=\left(\frac{Z_{\text {eff }}}{M}\right) N_{A} \sum n_{i}
$$

where $M=\sum n_{i} A_{i}$ is molar mass. $N_{A}$ is Avogadro number and $n_{i}$ is the number of formula units of $I^{\text {th }}$ element. $\left(\sigma_{e}\right)$ is the cross section/electron related to atomic cross section $\left(\sigma_{a}\right)$ as $\sigma_{e}=\frac{\sigma_{a}}{Z}$.

The atomic cross section and mass attenuation coefficient $(\mu / \rho)$ are related as $\mu / \rho=\frac{N_{A}}{Z} \sigma_{a}$.

\subsection{Half Value Layer (HVL)}


In an attenuating medium, half value layer (or half thickness) is defined as the thickness of any material which can reduce the intensity of incident gamma ray beam to one half of its original value.

HVL is related to the linear attenuation coefficient $\mu\left(\mathrm{cm}^{-1}\right)$ by the following relation

$$
\mathrm{HVL}=\frac{\ln (2)}{\mu}=\frac{0.693}{\mu}(\mathrm{cm})
$$

It is measured in units of length.

\section{Experimental Details}

\subsection{Collection and Preparation of Mixture}

Both Steel slag and Iron slags materials are by product of steel and iron industries respectively. Steel slag is taken from Modern Steel plant, situated at Mandi Gobindgarh whereas Iron slags (soft and hard type) have been collected from factories situated in local industrial area of Patiala. Large production and cheap availability of these materials pose a serious threat to our environment. That is why present work is undertaken and an attempt has been made to study the intensity of gamma radiation with the mixture of Steel slag (SS) and Iron slag with an intent to investigate the possibility of their utilization and disposal [19].

The test specimens were prepared according to specifications Bureau of Indian Standards. First, these materials were crushed and grinded separately so as to get powdered form. Both types of iron slags (soft and hard) are mixed together in equal proportions to get what may be called Mixed Iron Slag (MIS). Then steel slag is replaced by $0 \%, 10 \% 20 \%, 30 \%, 40 \%, 50 \%, 60 \%, 70 \%, 80 \%$, $90 \%$ in Mixed Iron Slag content by weight. The materials were weighed accurately and mixed properly. Cube moulds were filled with these mixtures and kept for $48 \mathrm{~h}$ in a casting room at a temperature of $25^{\circ} \mathrm{C}$ after which they were demoulded. The prepared ten samples were named as $\mathrm{IS}_{0}, \mathrm{IS}_{1}, \mathrm{IS}_{2}, \mathrm{IS}_{3}, \mathrm{IS}_{4}, \mathrm{IS}_{5}, \mathrm{IS}_{6}$, $\mathrm{IS}_{7}, \mathrm{IS}_{8}$ and $\mathrm{IS}_{9}$. A Pure flyash sample is also prepared for comparing results.

\subsection{Chemical Composition}

The chemical composition of Steel slag and MIS was determined by Energy dispersive $X$ ray analysis (EDX) available at Thapar University, Patiala. The weight percentage of different elements present in Steel slag-Iron mixtures are shown in Table 1. For comparison of their attenuation properties, weight percentage of pure flyash is given in Table 2 .

\subsection{Measurements of Transmitted Gamma Ray Spectra}

Narrow beam y-ray transmission geometry was used for the attenuation measurements of prepared specimens. The experimental setup of geometry is shown in Figure 1. The source was enclosed in a lead container with one face aperture 5 $\mathrm{mm}$, placed behind the source collimator. Three collimators with apertures 6 $\mathrm{mm}, 4 \mathrm{~mm}$ and $2.8 \mathrm{~mm}$ were placed with their front faces at a distance of 100 
$\mathrm{mm}, 240 \mathrm{~mm}$ and $515 \mathrm{~mm}$ from the source respectively. The width of each Table 1. Weight percentage of Steel slag-Iron mixtures.

\begin{tabular}{|c|c|c|c|c|c|c|c|c|c|c|}
\hline \multicolumn{11}{|c|}{ WEIGHT PERCENTAGE } \\
\hline ELEMENT & $\mathrm{IS}_{0}$ & IS $_{1}$ & $\mathrm{IS}_{2}$ & $\mathrm{IS}_{3}$ & $\mathrm{IS}_{4}$ & $\mathrm{IS}_{5}$ & $\mathrm{IS}_{6}$ & $\mathrm{IS}_{7}$ & $\mathrm{IS}_{8}$ & $\mathrm{IS}_{9}$ \\
\hline OXYGEN & 44.69 & 43.77 & 42.84 & 41.92 & 40.99 & 40.07 & 39.15 & 38.22 & 37.30 & 36.37 \\
\hline MAGNESIUM & 0 & 3.68 & 0.82 & 1.23 & 1.64 & 2.05 & 2.45 & 2.86 & 3.27 & 3.68 \\
\hline ALUMINIUM & 0.77 & 1.35 & 2.10 & 2.76 & 3.42 & 4.08 & 4.75 & 5.41 & 6.07 & 6.74 \\
\hline SILICON & 3.76 & 4.42 & 5.07 & 5.73 & 6.38 & 7.07 & 7.69 & 8.35 & 9.00 & 9.66 \\
\hline CALCIUM & 0 & 1.81 & 3.61 & 5.42 & 7.23 & 9.04 & 10.84 & 12.65 & 14.46 & 16.26 \\
\hline CHROMIUM & 0 & 0.09 & 0.19 & 0.28 & 0.37 & 0.47 & 0.56 & 0.65 & 0.744 & 0.84 \\
\hline IRON & 39.44 & 37.58 & 35.73 & 33.87 & 31.95 & 30.16 & 28.35 & 26.44 & 24.58 & 22.73 \\
\hline ZINC & 0 & 0.59 & 0.13 & 0.20 & 0.26 & 0.33 & 0.39 & 0.46 & 0.52 & 0.56 \\
\hline
\end{tabular}

Table 2. Weight percentage of flyash.

\begin{tabular}{ccccccccc}
\hline ELEMENTS & OXYGEN & ALUMINIUM & SILICON & POTASSIUM & CALCIUM & IRON & COPPER & ZINC \\
\hline WEIGHT\%AGE & 46.3 & 13.79 & 26.74 & 1.33 & 1.00 & 5.71 & 2.46 & 2.67 \\
\hline
\end{tabular}

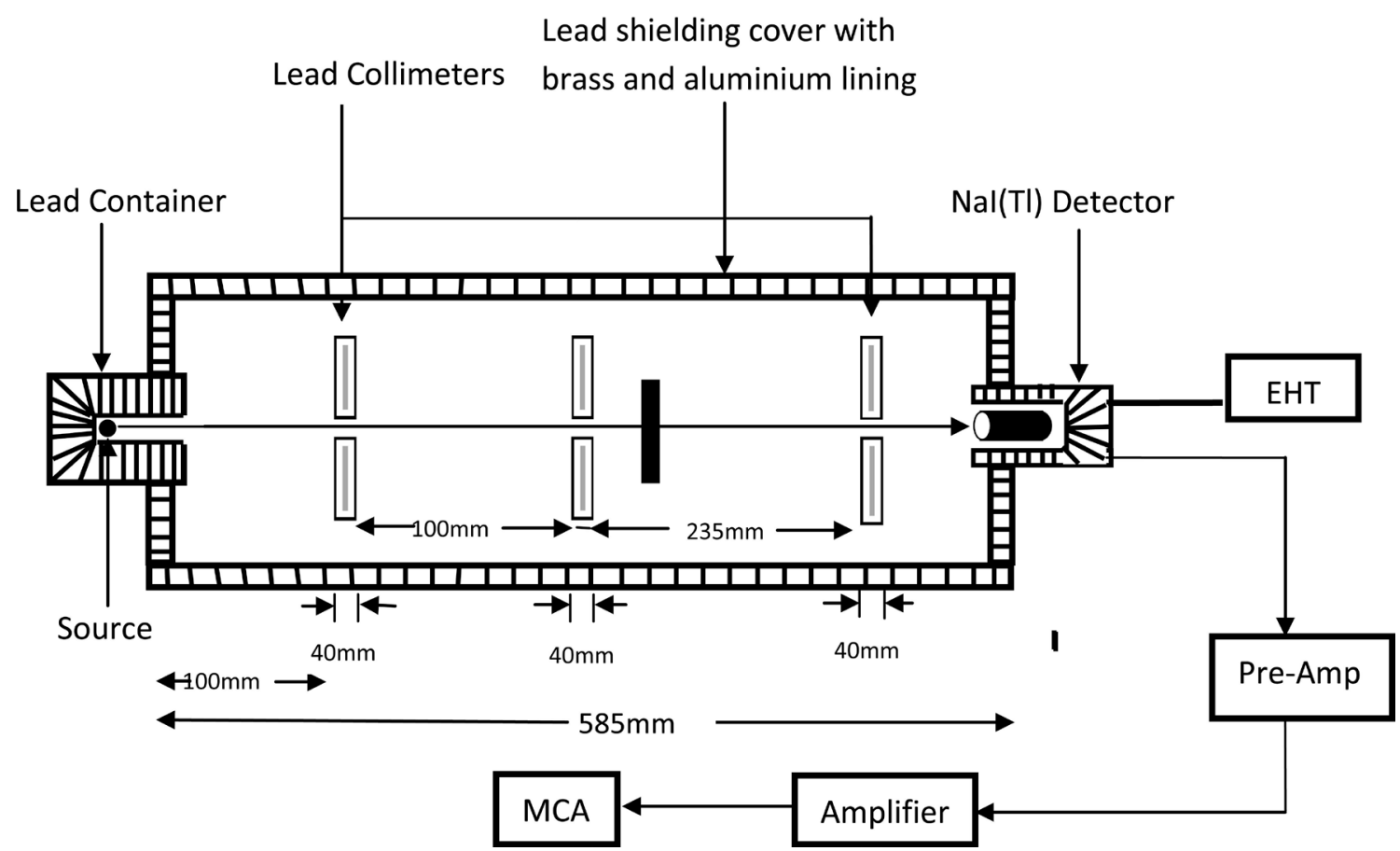

Figure 1. Experimental setup for narrow beam transmission geometry.

collimator was $40 \mathrm{~mm}$. The prepared samples were cubes of each side $5 \mathrm{~cm}$. Samples were positioned on specimen holder at a distance of $290 \mathrm{~mm}$ from the source. The distance between source and detector was held at $585 \mathrm{~mm}$. The detector was surrounded with proper lead shielding so as to prevent the scattered 
radiations from nearby objects reaching the detector. The total scatter acceptance angle $\left(\theta_{\mathrm{sc}}\right)[20]$ is the sum of the incidence beam divergence $\left(\theta_{\text {in }}\right)$ and angle subtended by exit collimation $\left(\theta_{\text {out }}\right)$. For the present geometry, the incidence beam divergence was $1.63^{\circ}$ and the acceptance angle at the detector was $0.72^{\circ}$. Overall scatter acceptance angle was $2.6^{\circ}$. For this value of scatter acceptance angle, the scattered radiation reaching the detector can cause a ray-sum error of $0.5 \%-1.0 \%$ which falls within the tolerating limits.

The model 802 scintillation detector of $3 \times 3 \mathrm{NaI}(\mathrm{Tl})$ type was used in the study. It was enclosed in a hermetically sealed assembly which includes a high resolution $\mathrm{NaI}(\mathrm{TI})$ crystal, a PMT with a pre-amplifier, an internal magnetic/ light shield, an aluminium housing and a 14-pin connector. The reliability and stability of the geometrical setup was tested using aluminium as a reference absorber at $662 \mathrm{keV}$. The spectrum was recorded for sufficient long time so as to reduce statistical error in counts less than $0.3 \%$. The best resolution $7.5 \%$ was obtained for the $662 \mathrm{keV}$ gamma ray from Cs-137 source. The background counts recorded for the same time were subtracted from each spectrum. To stop the fluorescence X-rays of lead entering in the detector, the lead shield was lined on the inside and with brass and aluminium sheets outside. The experiment was conducted at constant low temperature to avoid shifting of spectrum peak.

\section{Results and Discussion}

The incident $\left(I_{o}\right)$ and transmitted $(I)$ y-ray intensities have been measured for experimentally determining the values of mass attenuation coefficients of specimens. The experimental values of mass attenuation coefficient obtained using Equation (1) are enlisted in Table 3, together with the theoretical values, calculated using the winXCOM computer program [21]. The maximum errors in mass attenuation coefficient were calculated from errors in the incident $\left(I_{o}\right)$ and transmitted $(I)$ intensities, mass density $(\rho)$ and thickness $(t)$ using the propagation of error formula:

Table 3. Mass attenuation values for Steel slag-Iron samples at various energies.

\begin{tabular}{|c|c|c|c|c|c|c|c|c|c|c|}
\hline \multirow{2}{*}{ SAMPLE } & \multicolumn{2}{|c|}{$60 \mathrm{KeV}$} & \multicolumn{2}{|c|}{$136 \mathrm{KeV}$} & \multicolumn{2}{|c|}{$662 \mathrm{KeV}$} & \multicolumn{2}{|c|}{$1173 \mathrm{KeV}$} & \multicolumn{2}{|c|}{$1332 \mathrm{KeV}$} \\
\hline & Exp. & Theo. & Exp. & Theo. & Exp. & Theo. & Exp. & Theo. & Exp. & Theo. \\
\hline $\mathrm{IS}_{0}$ & 0.600 & 0.601 & 0.176 & 0.174 & 0.0758 & 0.0757 & 0.0584 & 0.0574 & 0.0547 & 0.0538 \\
\hline IS $_{1}$ & 0.598 & 0.599 & 0.176 & 0.174 & 0.0758 & 0.0757 & 0.0586 & 0.0574 & 0.0550 & 0.0538 \\
\hline $\mathrm{IS}_{2}$ & 0.589 & 0.590 & 0.171 & 0.173 & 0.0759 & 0.0758 & 0.0579 & 0.0574 & 0.0541 & 0.0538 \\
\hline $\mathrm{IS}_{3}$ & 0.584 & 0.585 & 0.174 & 0.173 & 0.0759 & 0.0758 & 0.0576 & 0.0575 & 0.0533 & 0.0539 \\
\hline $\mathrm{IS}_{4}$ & 0.582 & 0.579 & 0.171 & 0.172 & 0.0758 & 0.0759 & 0.0578 & 0.0575 & 0.0535 & 0.0539 \\
\hline $\mathrm{IS}_{5}$ & 0.577 & 0.574 & 0.171 & 0.172 & 0.0760 & 0.0759 & 0.0565 & 0.0576 & 0.0537 & 0.0539 \\
\hline $\mathrm{IS}_{6}$ & 0.564 & 0.569 & 0.172 & 0.171 & 0.0761 & 0.0760 & 0.0565 & 0.0576 & 0.0531 & 0.0540 \\
\hline $\mathrm{IS}_{7}$ & 0.558 & 0.563 & 0.170 & 0.171 & 0.0761 & 0.0760 & 0.0563 & 0.0576 & 0.0528 & 0.0540 \\
\hline $\mathrm{IS}_{8}$ & 0.556 & 0.557 & 0.172 & 0.171 & 0.0762 & 0.0761 & 0.0566 & 0.0577 & 0.0530 & 0.0541 \\
\hline
\end{tabular}




\section{$\mathrm{IS}_{9}$ 0.551 0.552 0.169

$0.170 \quad 0.0762$

0.0761

0.0567

0.0577 \\ 0.0530 0.0541

$$
\Delta\left(\frac{\mu}{\rho}\right)=\frac{1}{\rho t} \sqrt{\left(\frac{\Delta I o}{I o}\right)^{2}+\left(\frac{\Delta I}{I}\right)^{2}+\left(\ln \frac{I o}{I}\right)^{2}\left[\left(\frac{\Delta \rho}{\rho}\right)^{2}+\left(\frac{\Delta t}{t}\right)^{2}\right]}
$$

where $t$ is the sample thickness in centimetres, and are the errors in the intensities $I_{o}, I$, density and thickness $t$ of the sample respectively. It was found that the estimated error in experimental measurements was less than $3.7 \%$. The experimental results are in good agreement with the theoretical results within estimated errors.

The linear attenuation coefficient $\mu\left(\mathrm{cm}^{-1}\right)$ is shown graphically as a function of given photon energies in Figure 2. As density of samples do not change so much with increase in steel slag, therefore, mass attenuation coefficients as well as linear attenuation coefficients remain constant because first is independent of density of the material and depend only upon the chemical composition of the material The variations in $(\mu / \rho)$ values and linear attenuation coefficients $(\mu)$ at different energies are interpreted as being due to the dominance and $Z$-dependence of different partial photon interaction processes in different energy regions. In low energy region $(60,136 \mathrm{KeV})$, the variation of $\mu_{m}$ (Total) and $\mu$ $\left(\mathrm{cm}^{-1}\right)$ is mainly due to Photo electric process and also less, but significantly due to coherent scattering. Photo electric process is $Z^{4-5}$ dependent whereas coherent scattering has $Z^{2-3}$ dependence. Moreover, sharp decrease in both $\mu_{m}$ and $\mu$ $\left(\mathrm{cm}^{-1}\right)$ in low energy region is due to the fact that Photo electric cross section is inversely proportional to $E^{3.5}$ in the intermediate energy region $(662 \mathrm{KeV}-1332$ $\mathrm{KeV})$.

For the (MIS + SS) specimens, effective atomic numbers have been determined from the mass attenuation coefficients. The obtained values of effective atomic numbers are shown graphically in Figure 3. The results in present investigations clearly support the view points of Hine (1952). The trend in variation 


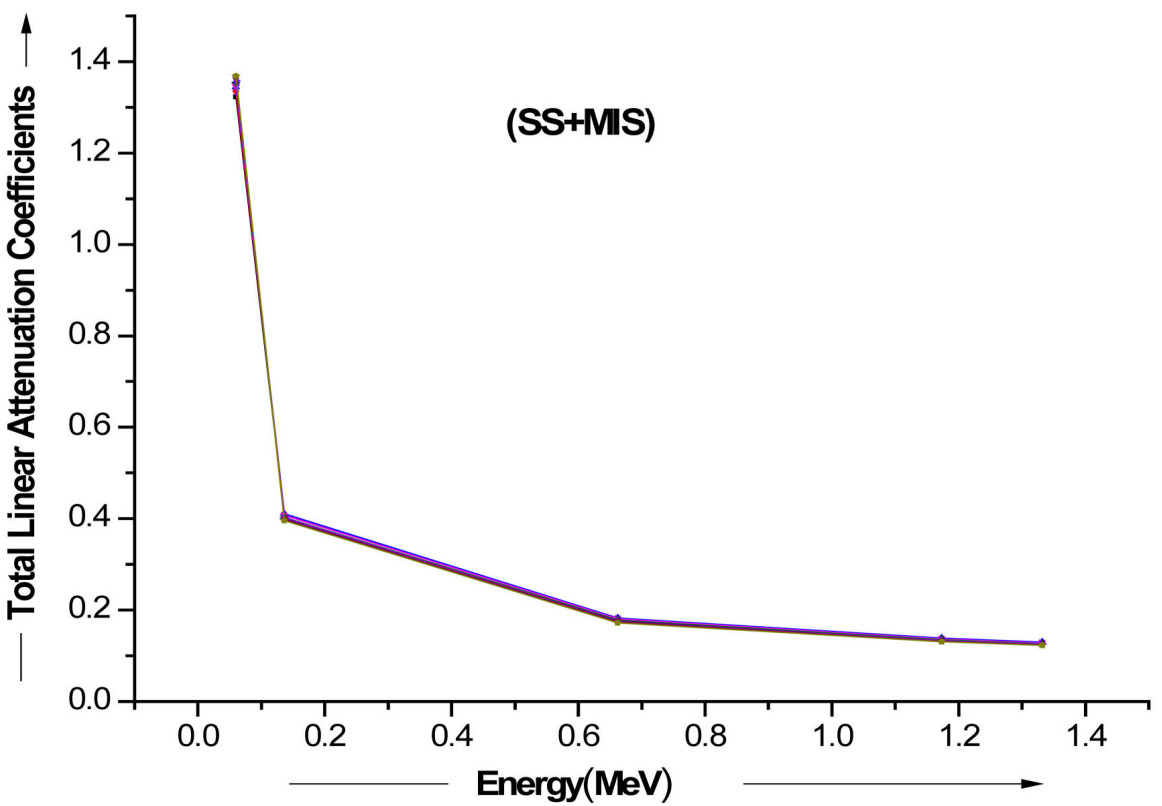

Figure 2. Variation of Linear attenuation coefficients with energy.

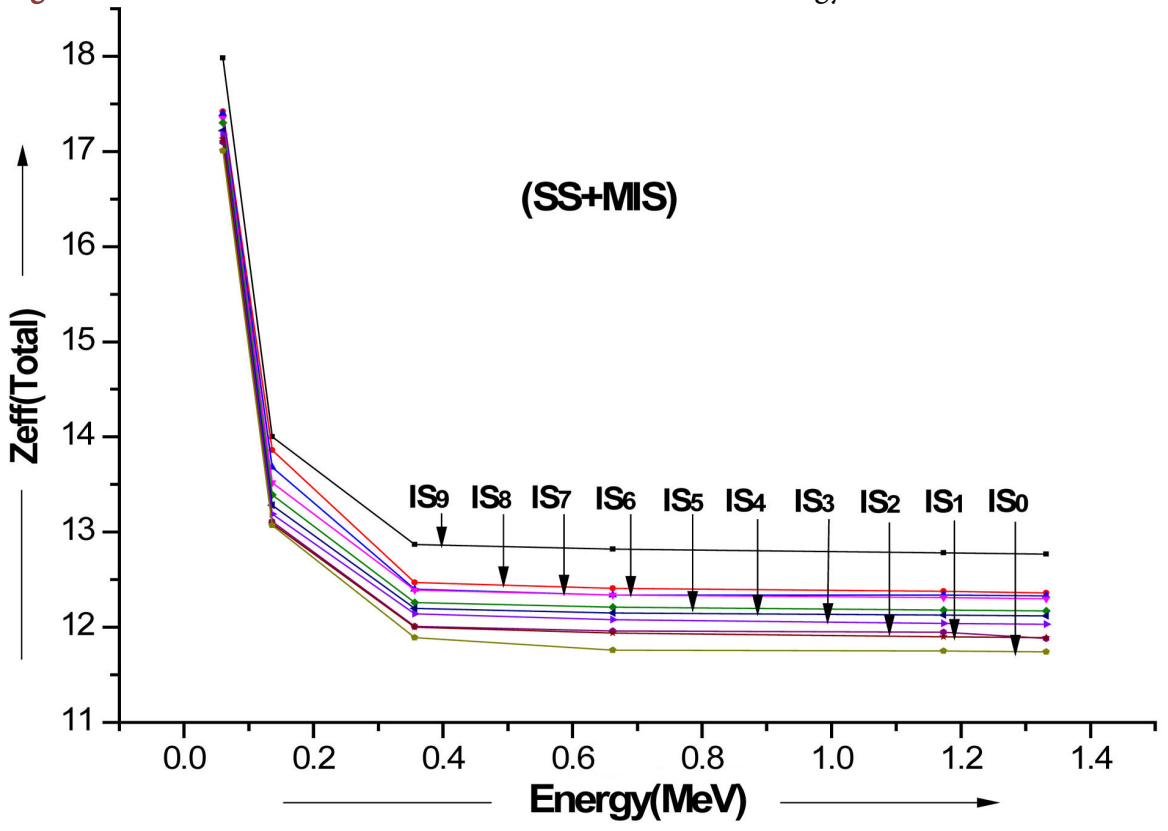

Figure 3. Variation of $Z_{\text {eff }}$ with energy.

Table 4. Electron density values $\left(\times 10^{23}\right)$ of Steel slag-Iron samples at various energies.

\begin{tabular}{ccccccccccc}
\hline \multirow{2}{*}{ SAMPLE } & \multicolumn{2}{c}{$60 \mathrm{KeV}$} & \multicolumn{2}{c}{$136 \mathrm{KeV}$} & \multicolumn{2}{c}{$662 \mathrm{KeV}$} & \multicolumn{2}{c}{$1173 \mathrm{KeV}$} & \multicolumn{2}{c}{$1332 \mathrm{KeV}$} \\
\cline { 2 - 11 } & Exp. & Theo. & Exp. & Theo. & Exp. & Theo. & Exp. & Theo. & Exp. & Theo. \\
\hline IS $_{0}$ & 4.24 & 4.17 & 3.26 & 3.28 & 2.93 & 2.94 & 2.93 & 2.98 & 2.93 & 2.97 \\
IS $_{1}$ & 4.24 & 4.24 & 3.25 & 3.27 & 2.96 & 2.95 & 2.95 & 3.02 & 2.95 & 2.99 \\
IS $_{2}$ & 4.23 & 4.22 & 3.24 & 3.26 & 2.95 & 2.94 & 2.95 & 2.96 & 2.95 & 2.97 \\
IS $_{3}$ & 4.21 & 4.14 & 3.23 & 3.25 & 2.96 & 2.95 & 2.95 & 2.96 & 2.93 & 2.92 \\
IS $_{4}$ & 4.20 & 4.21 & 3.24 & 3.22 & 2.96 & 2.95 & 2.95 & 2.98 & 2.95 & 2.94 \\
\hline
\end{tabular}




\begin{tabular}{lllllllllll}
\hline IS $_{5}$ & 4.19 & 4.03 & 3.24 & 3.23 & 2.96 & 2.98 & 2.95 & 2.91 & 2.94 & 2.93 \\
IS $_{6}$ & 4.18 & 4.06 & 3.26 & 3.27 & 2.97 & 2.99 & 2.96 & 2.93 & 2.95 & 2.92 \\
IS $_{7}$ & 4.17 & 4.02 & 3.28 & 3.26 & 2.97 & 2.98 & 2.96 & 2.92 & 2.96 & 2.91 \\
IS $_{8}$ & 4.15 & 4.08 & 3.30 & 3.31 & 2.96 & 2.96 & 2.95 & 2.91 & 2.95 & 2.90 \\
IS $_{9}$ & 4.14 & 4.14 & 3.23 & 3.21 & 2.96 & 2.97 & 2.95 & 2.90 & 2.95 & 2.91 \\
\hline
\end{tabular}

of $Z_{\text {eff }}$ with variation in steel slag content at given energies $(60,136,662,1173$, $1332 \mathrm{KeV})$ is same as that of $\mu_{m}$ or $\mu\left(\mathrm{cm}^{-1}\right)$. With the increase in steel slag content, effective atomic numbers of specimens do not change much. The present results are in line with the results of Lingam et al. (1984), Parthasaradhi (1968) and Modi et al. (1991) in the covered energy region. In the energy region of 662 to $1332 \mathrm{KeV}$, the values of effective atomic number are almost constant which is also in line with the viewpoint of El-Kateb and Abdul Hamid.

The computed electron density values using Equation (4) are shown in Table 4. The electron density for all the specimens varies in the range of ((2.93 - 4.24) $\times 10^{23}$ ) electrons per unit gram of the material.

The values of half value layer (HVL) of the prepared specimens were computed using Equation (5) and are shown graphically in Figure 4.

From the obtained results, it is observed that, half value layer increases with increase in energy and with decrease in steel slag content. To assess the shielding ability [22] of a material, half value layer (HVL) is inversely related to shielding effectiveness. With the increase in energy, (HVL) increases, because to reduce intensity of incident gamma radiations to one half, more thickness of the target will be required. Also, with decrease in steel slag content, (HVL), increases slightly. This is attributed to small decrease in linear attenuation coefficients with decrease in steel slag content (Figure 2). It is clear that, (HVL), for any (MIS + SS) sample is very much lower than Pure Flyash at all the given energies. It means that (MIS + SS) mixtures are better in gamma ray shielding than Pure Flyash at all the given energies. The mass attenuation coefficients, $\mu_{m}$ of all the samples were also computed with the help of a state of-the-art convenient computer programme WinXCOM, initially developed by Berger and Hubble and later modified to window version by Gerward et al. (2004). This programme was run on a personal computer. For the computation of $\mu_{m}(\mu / \rho)$, the chemical composition of each sample was supplied to the programme. The mass attenuation coefficient $\mu / \rho$ in $\mathrm{cm}^{2} / \mathrm{g}$ of each sample was computed. From the results obtained, other interaction parameters were also computed.

\section{Applications/Utilizations}

Both slags are environmentally hazardous materials and are being produced in huge amounts every day. So, their utilization and disposal is a matter of serious concern. Taking into consideration their attenuation abilities, these materials can be used for radiation shielding if properly compacted or admixed with concrete. Slag mixed concretes are most suitable especially where huge structures 
are required e.g., Nuclear reactors, Underground bunkers for protection against Nuclear experiments or testing Nuclear weapons etc. These structures become

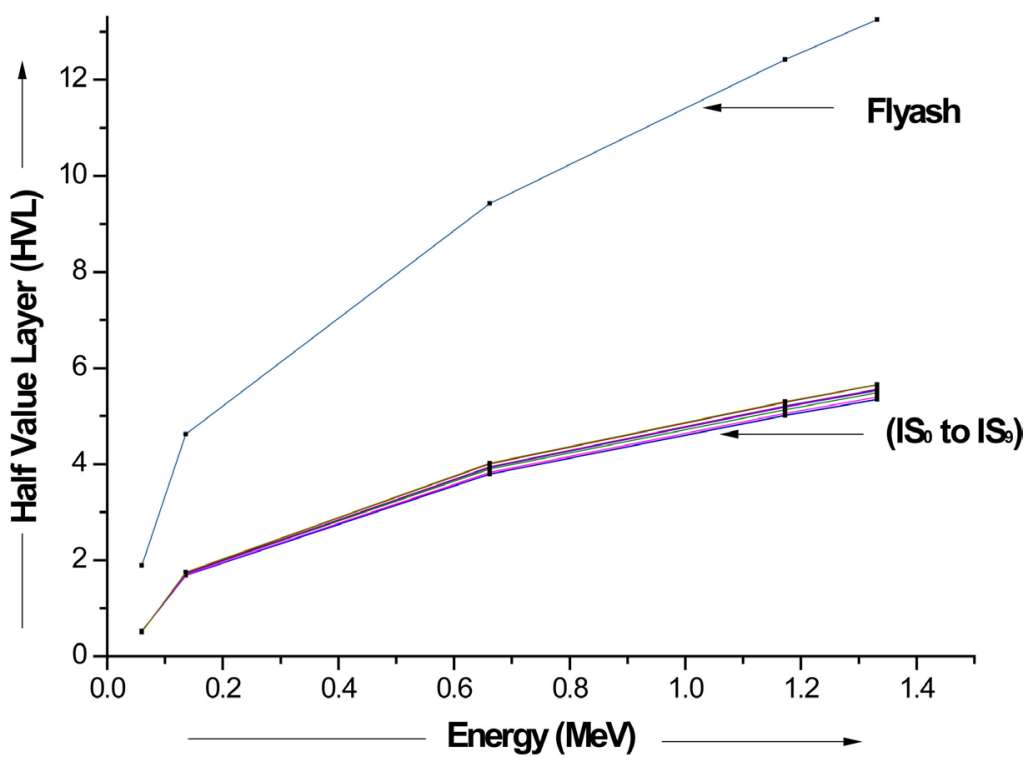

Figure 4. Variation of (HVL) of (MIS + SS) with incident energy.

more durable, economical as well as eco-friendly when slags are used in concretes. The reason is that concrete develop micro-cracks due to higher level of hydration and porosity. Also, variation in composition and large water content leads to decrease of density and structure strength of concretes. As slags contain silica, which converts free lime present in concretes into insoluble calcium silicate hydrates that decreases heat of hydration, thereby reducing cracks in concretes. It also provides strength to concretes at later ages.

\section{Conclusion}

The performance of a concrete radiation shield with slags is improved effectively. Though, flyash is also used as an aggregate in making radiation shields its density is far less than slag. Thus, effective attenuation ability of slag is more than that of flyash. The comparison of gamma ray shielding properties of steel slag + iron slag mixtures with Pure Flyash at various gamma ray energies shows that the mixtures are more suitable than Pure Flyash in shielding gamma radiations. Keeping in view these facts and their utilization, steel slag + iron slag mixture is more appropriate for making shields as well as in other construction activities.

\section{References}

[1] Singh, H., Singh, K., Sharma, G., Nathuram, R. and Sahota, H.S. (2002) Photon Interaction Studies with Some Glasses and Building Materials. Nuclear Science and Engineering. The Journal of the American Nuclear Society (Nucl. Sci. Eng.), 142, 342-348.

[2] Singh, K., Singh, C., Singh, P.S. and Mudahar, G.S. (2002) Effect of Weight Fraction of Different Constituent Elements on the Total Mass Attenuation Coefficients of 
Biological Materials. Pramana, 59, 151-154. https://doi.org/10.1007/s12043-002-0039-y

[3] Singh, M. and Mudahar, G.S. (1992) Energy Dependence of Total Photon Attenuation Coefficients of Composite Materials. Applied Radiation and Isotopes, 43, $907-$ 911. https://doi.org/10.1016/0883-2889(92)90154-7

[4] Singh, M. and Mudahar, G.S. (1993) Effects of Sample Thickness on the Measured Mass Attenuation Coefficients Perspex and Bakelite. Ind. J. Phys., 67, 79.

[5] Mudahar, G.S., Modi, S. and Makhan, S. (1991) Total and Partial Mass Attenuation Coefficients of Soil as a Function of Chemical Composition. Applied Radiation and Isotopes, 42, 13-18. https://doi.org/10.1016/0883-2889(91)90118-K

[6] El-Kateb, A.H. and Hamid, A.A.S. (1991) Photon Attenuation Coefficient Study of Some Materials Containing Hydrogen, Carbon and Oxygen. Applied Radiation and Isotopes, 42, 303-307. https://doi.org/10.1016/0883-2889(91)90093-G

[7] Bashter, I.J. (1997) Calculation of Radiation Attenuation Coefficients for Shielding Concretes. Annals of Nuclear Energy, 24, 1389-1401.

https://doi.org/10.1016/S0306-4549(97)00003-0

[8] Alam, M.N., Miah, M.M.H., Chowdhury, M.L., Kamal, M., Ghose, S. and Rahman, R. (2001) Attenuation Coefficients of Soils and Some Building Materials of Bangladesh in the Energy Range 276 - $1332 \mathrm{KeV}$. Applied Radiation and Isotopes, 54, 973 976. https://doi.org/10.1016/S0969-8043(00)00354-7

[9] Akkurt, L., Kitincarsian, S. and Basyigit, C. (2004) The Photon Attenuation Coefficients of Barite, Marble and Limra. Annals of Nuclear Energy, 31, 577-582. https://doi.org/10.1016/j.anucene.2003.07.002

[10] Berger, M.J. and Hubble, J.H. (1987) Photon Cross-Section on a Personal Computer. National Institute of Standards and Technology, Gaithersburg, MD. NBBI R87, 3597.

[11] Hine, G.J. (1952) The Effective Atomic Number of Materials for Various Gamma Ray Interactions. Phys. Rev., 85, 725.

[12] Lingam, S.C., Basu, K.S. and Reddy, D.V.K. (1984) Total Gamma Ray Cross Sections and Effective Atomic Numbers in Compounds in the Energy Region 32 to 662 $\mathrm{keV}$. Indian Journal of Physics, 58, 285.

[13] Mudahar, G.S. and Singh, M. (1991) Energy Dependence of the Effective Atomic Number of Alloys. Applied Radiation and Isotopes, 42, 509-512. https://doi.org/10.1016/0883-2889(91)90153-R

[14] Parthasaradhi, K. (1968) Studies on Effective Atomic Numbers in Alloys for Gamma Ray Interaction in the Energy Region 100 - $662 \mathrm{KeV}$. Indian Journal of Pure and Applied Physics, 6, 609.

[15] Sahota, H.S. and Mudahar, G.S. (1988) Effective Atomic Number Studies in Different Soils for Total Photon Interaction in Energy Region 10-Effective5000 KeV. Applied Radiation and Isotopes, 39, 1251-1254. https://doi.org/10.1016/0883-2889(88)90108-6

[16] Un, A. and Demir, F. (2013) Determination of Mass Attenuation Coefficients, Effective Atomic Numbers and Electronic Electron Numbers for Heavy-Weight and Normal-Weight Concretes. Applied Radiation and Isotopes, 80, 73-77. https://doi.org/10.1016/j.apradiso.2013.06.015

[17] Kore, P.S. and Pawar, P. (2014) Measurements of Mass Attenuation Coefficient, Effective Atomic Number and Electron Density of Some Amino Acids. Radiat. Phys. Chem., 98.

[18] Gowda, S., Krishnaveni, S., Yashoda, T., Umesh, T.K. and Gowda, R. (2004) Photon 
Mass Attenuation Coefficients, Effective Atomic Number and Electron Density of Some Thermoluminescent Dosimetric Compounds. Pramana, 63, 529-541. https://doi.org/10.1007/BF02704481

[19] Nadeem, M. and Pofale, A.D. (2012) Experimental Investigation of Using Slag as an Alternative to Normal Aggregate (Coarse and Fine) in Concrete. International Journal of Civil and Structural Engineering, 3, 117-127.

[20] Midgley, S. (2006) Angular Width of a Narrow Beam for X-Ray Linear Attenuation Coefficient Measurements. Radiation Physics and Chemistry, 75, 945-953. https://doi.org/10.1016/j.radphyschem.2006.01.008

[21] Gerward, L., Guilbert, N., Jensen, K.B. and Levring, H. (2004) WinXCOM-A Programme for Calculating X-Ray Attenuation. Radiation Physics and Chemistry, 71, 653-654. https://doi.org/10.1016/j.radphyschem.2004.04.040

[22] Singh, K., Singh, S., Dhaliwal, A.S. and Singh, G. (2015) Gamma Radiation Shielding Analysis of Lead-Flyash Concretes. Applied Radiation and Isotopes, 95, 174179. https://doi.org/10.1016/j.apradiso.2014.10.022 